\title{
Daclizumab Therapy for Multiple Sclerosis
}

\author{
Bibiana Bielekova
}

Published online: 5 October 2012

(C) The American Society for Experimental NeuroTherapeutics, Inc. (outside the U.S.) 2012

\begin{abstract}
Daclizumab is a humanized monoclonal antibody of IgG1 subtype that binds to the Tac epitope on the interleukin-2 (IL-2) receptor $\alpha$-chain (CD25), thus, effectively blocking the formation of the high-affinity IL-2 receptor. Because the high-affinity IL-2 receptor signaling promotes expansion of activated T cells in vitro, daclizumab was designed as a therapy that selectively inhibits T-cell activation. Assuming the previous statement, daclizumab received regulatory approval as add-on therapy to standard immunosuppressive regimen for the prevention of acute allograft rejection in renal transplantation. Based on its putative mechanism of action (MOA), daclizumab represented an ideal therapy for T-cell-mediated autoimmune diseases and was subsequently tested in inflammatory uveitis and multiple sclerosis (MS). In both of these diseases, daclizumab therapy significantly inhibited target organ inflammation. Mechanistic studies in MS demonstrated that the MOA of daclizumab is surprisingly broad and that the drug exerts unexpected effects on multiple components of the innate immune system. Specifically, daclizumab dramatically expands and activates immunoregulatory CD $56^{\text {bright }}$ NK cells, which gain access to the intrathecal compartment in MS and can kill autologous activated T cells. Daclizumab also blocks trans-presentation of IL-2 by mature dendritic cells to primed $\mathrm{T}$ cells, resulting in profound inhibition of
\end{abstract}

Electronic supplementary material The online version of this article (doi:10.1007/s13311-012-0147-4) contains supplementary material, which is available to authorized users.

B. Bielekova $(\square)$

Neuroimmunological Diseases Unit (NDU), Neuroimmunology

Branch (NIB), National Institute of Neurological Disorders and Stroke (NINDS),

Bethesda, MD 20892, USA

e-mail: Bibi.Bielekova@nih.gov

B. Bielekova

National Institutes of Health (NIH),

Bethesda, MD 20892, USA antigen-specific T cells. Finally, daclizumab modulates the development of innate lymphoid cells. In conclusion, daclizumab therapy, which is currently in phase III testing for inflammatory MS, has a unique MOA that does not limit migration of immune cells into the intrathecal compartment, but rather provides multifactorial immunomodulatory effects with resultant inhibition of MS-related inflammation.

Keywords Multiple sclerosis · Autoimmunity · Biological therapy $\cdot \mathrm{IL}-2 \cdot \mathrm{CD} 25$

\section{Introduction}

Interleukin (IL)-2 has been called "T cell growth factor" [1, 2], because since its discovery it has been used for in vitro expansion of $\mathrm{T}$ cells. Indeed, upon activation by the T-cell receptor (TCR), T cells start expressing on their surface high levels of heterotrimeric "high affinity" IL-2 receptor (IL-2R) (Fig. 1). At approximately the same time when the surface expression of IL-2R peaks (i.e., $48-72 \mathrm{~h}$ post-stimulation), naïve $T$ cells that have received an antigen-specific signal also start producing large quantities of IL-2. Therefore, it was believed that this autocrine IL-2 signaling loop mediates clonal expansion of activated $\mathrm{T}$ cells and promotes development of their effector functions. The induction of IL-2R on activated $\mathrm{T}$ cells is proportional to the strength of the TCR stimulus [3]; thus, T cells that receive higher antigen-specific stimulus compete better for a subsequent IL-2 signal. This observation further reinforced the idea that IL-2 promotes T-cell immunity. As a consequence, it was believed that blockade of IL-2 signaling would inhibit T-cell effector functions. This represented the basis for the notion that CD25-targeting therapies are the ideal treatment for prevention of rejection of allogeneic transplants or for inhibition of autoimmunity and chronic inflammation [4-6]. The first such therapeutic agent targeting IL-2 signaling 
pathway was daclizumab [7]. The intramural National Institutes of Health (NIH) played a decisive role in the development of this biological therapy and in defining its mechanism of action (MOA).

\section{IL-2 Receptor System and Its Expression on Resting versus Activated T Cells}

To be able to understand the effects of daclizumab on the human immune system, we need to first review the biology of IL-2 signaling. The high-affinity IL-2R consists of 3 chains: 2 signaling molecules, 1) $\gamma$-chain (CD132) and 2) $\beta$-chain (CD122), and 3) the nonsignaling $\alpha$-chain (CD25) (Fig. 1) [8]. An interesting feature of cytokine receptors is the sharing of their signaling molecules; hence, the $\gamma$-chain is also called common $\gamma$-chain $\left(\gamma_{\mathrm{c}}\right)$, because it is used by a wide array of cytokines (IL-2, IL-4, IL-7, IL-15, and IL-21), whereas the $\beta$-chain is shared by 2 closely-related cytokines (IL-2 and IL-15) [9]. We are now only beginning to appreciate that such sharing of signaling chains has important functional consequences, due to competition for limited quantities of different cytokines.

Constitutive expression of $\gamma_{\mathrm{c}}$ on resting T cells underlies their responsiveness to cytokines that mediate T-cell homeostasis and survival, such as IL-7. Resting human T cells also express low levels of IL-2R $\beta$-chain, allowing them to receive IL-15 signal, and potentially also IL-2 signal under conditions of IL-2 abundance. However, only a subgroup of resting CD4 $+\mathrm{T}$ cells, called T-regulatory cells (T-regs), which are dependent on the transcriptional factor FoxP3, express constitutively high levels of CD25. Therefore, only resting T-regs are capable of binding low concentrations of IL-2, which is required for their in vivo survival and immunoregulatory functions [10]. Because of their expression of high-affinity IL-2R, T-regs can successfully "steal" the limited amounts of IL-2 secreted by weakly stimulated T cells,

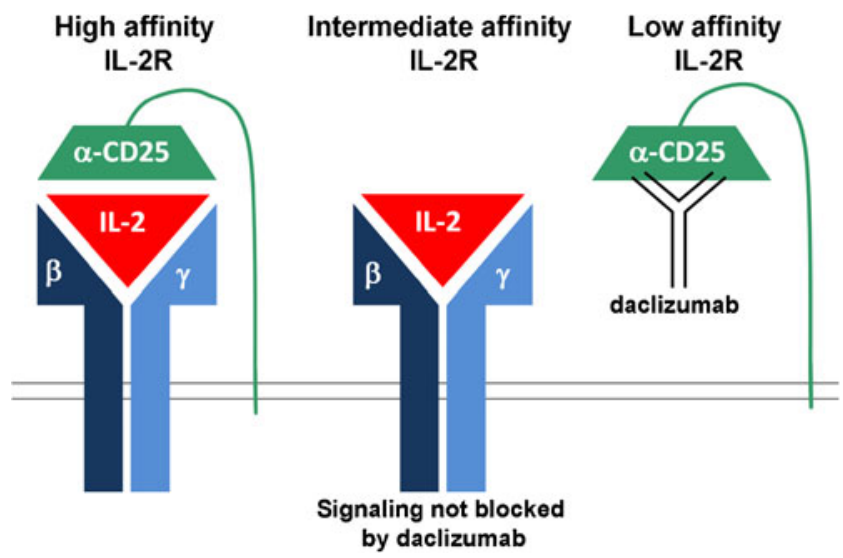

Fig. 1 Schematics of the 3 interleukin-2 receptors (IL-2R) and daclizumab binding site which represents 1 of the several mechanisms of T-regmediated immunoregulation of effector $\mathrm{T}$ cells [3]. Although expression of $\beta$ - and $\gamma$-chain of IL-2R, which together form the "intermediate affinity IL-2R" (Fig. 1) is sufficient to mediate IL-2 signaling when IL-2 concentrations are relatively high $(\mathrm{Kd}=1 \mathrm{nM})$, T cells that express $\mathrm{CD} 25$ can respond to 10 to 100 -fold lower concentrations of IL-2 $(\mathrm{Kd}=10 \mathrm{pM})$ [11]. This explains why T-regs win the tug-of-war with weakly stimulated effector $\mathrm{T}$ cells for the limited concentrations of IL-2 [3]. CD25 itself has a very limited affinity for IL-2 $(\mathrm{Kd}=10 \mathrm{nM})$, and therefore this nonsignaling chain is called the "low affinity IL-2R" (Fig. 1) [11].

\section{Development of Daclizumab as a Therapeutic}

Daclizumab is a humanized monoclonal antibody $(\mathrm{mAb})$ of immunoglobulin (Ig)G1 subtype [7] that blocks the interaction of CD25 with IL-2 (via the so-called "Tac" epitope) (Fig. 1). As a consequence, daclizumab blocks low-affinity and high-affinity IL-2R, whereas it has no effect on IL-2 signaling through the intermediate affinity IL-2R. As indicated as follows, this property of daclizumab has important functional consequences for different types of immune cells.

Because CD25 is upregulated on effector T cells, it was believed that daclizumab would selectively inhibit this activated state of T cells. Undeniably, daclizumab, or its original murine anti-Tac $\mathrm{mAb}$, which was developed in the laboratory of Thomas Waldmann in the intramural NIH/National Cancer Institute (NCI), inhibits T-cell signaling to IL-2 in vitro and in vivo [12-14]. Subsequent demonstration that addition of daclizumab to standard immunosuppressive regimens (i.e., cyclosporine and steroids) provided clinical benefit for the prevention of the rejection of allogeneic renal transplants [5], was fully in agreement with this putative MOA on effector T cells.

Based on these data, after commercialization of daclizumab and its regulatory approval as adjunctive therapy for preventing rejection of allogeneic solid organ transplants (i.e., Zenapax; Hoffmann-La Roche), the efficacy of daclizumab was tested in the intramural NIH in chronic human inflammatory conditions, such as HTLV-1 associated myelopathy/tropical spastic paraparesis [15] and inflammatory uveitis [16, 17]. Although in HTLV-1-associated myelopathy/tropical spastic paraparesis short-term application of daclizumab decreased HTLV-1 pro-viral load and inhibited spontaneous lymphoproliferation of activated T cells, experience in inflammatory uveitis demonstrated a clear clinical benefit of long-term daclizumab treatment.

Both these observations were consistent with the presumed inhibitory effect of daclizumab on effector $\mathrm{T}$ cells. Thus, in 1999, again in the intramural NIH/National Institute 
of Neurological Disorders and Stroke (NINDS), we initiated a phase I/II clinical trial of daclizumab in multiple sclerosis chronic inflammatory/demyelinating condition (MS) of the central nervous system (CNS) (the Zenapax to Treat Multiple Sclerosis study; Clinicaltrials.gov identifier: NCT00001934). The clinical protocol was shared with a second center at the University of Utah and in both of these pilot MS studies, addition of daclizumab to patients who had an inadequate clinical and radiological response to interferon- $\beta$ (IFN- $\beta$ ) resulted in $>80 \%$ inhibition of contrast-enhancing lesions (CEL) on brain magnetic resonance imaging (MRI) and stabilization of clinical disease activity $[18,19]$. Later, both centers amended their protocols to study the long-term effects of daclizumab on MS disease activity after withdrawal of IFN- $\beta[20,21]$. These studies demonstrated that in the majority of MS patients, IFN- $\beta$ could be withdrawn after 6 months of IFN- $\beta /$ daclizumab combination therapy without decline in clinical efficacy of long-term daclizumab monotherapy. However, 1 of these studies [20] also demonstrated that IFN- $\beta$ and daclizumab have synergistic effects, and optimal response in one third of patients required either continuation of IFN- $\beta /$ daclizumab combination therapy or a higher dose of daclizumab monotherapy (i.e., $2 \mathrm{mg} / \mathrm{kg}$ intravenously every 4 weeks instead of the traditional $1 \mathrm{mg} / \mathrm{kg}$ intravenously every 4 weeks). This observation was puzzling, because the standard dose of $1 \mathrm{mg} / \mathrm{kg}$ already led to $100 \%$ saturation of CD25 Tac epitope on peripheral blood mononuclear cells [18]. We will get back to this point when discussing new results of the MOA of daclizumab on the human immune system.

Because all of the aforementioned studies focused on a subgroup of MS patients who had high breakthrough activity on IFN- $\beta$ (and most of these patients had a partial therapeutic response to IFN- $\beta$ [i.e., they generally did not represent subjects with neutralizing antibody against IFN$\beta]$ ), then the question remained whether daclizumab monotherapy in treatment-naïve MS subjects would be equally effective. This question was answered in a new phase II clinical trial (the Zenapax (Daclizumab) to Treat Relapsing Remitting Multiple Sclerosis trial; Clinicaltrials.gov identifier: NCT00071838), in which comparable levels of MRI efficacy and stabilization/improvement of clinical outcomes was observed [22].

However, because these studies were all open-label, baseline versus treatment clinical trials, the efficacy of daclizumab on MS disease activity had to be reproduced in placebo-controlled studies. This was accomplished in 2 multicenter phase II trials sponsored by the pharmaceutical industry: specifically in the CHOICE study (the Study of Subcutaneous Daclizumab in Patients With Active, Relapsing Forms of Multiple Sclerosis; Clinicaltrials.gov identifier: NCT00109161) [23], which investigated IFN- $\beta$ /daclizumab combination therapy and in the phase 2 SELECT trial (the Safety and Efficacy Study of Daclizumab
HYP to Treat Relapsing Remitting Multiple Sclerosis trial; Clinicaltrials.gov identifier: NCT00870740), which investigated daclizumab monotherapy. This last study used a new preparation of daclizumab called daclizumab high-yield process (DAC HYP), which shares an identical amino-acid sequence with the original Zenapax preparation, but a different production process resulted in changes in the glycosylation pattern of the molecule, which affected the binding of daclizumab to $F_{c}$ receptors. As reviewed elsewhere [24], binding of $m A b$ to $F_{c}$ receptors can significantly modify the outcome of $m A b$ therapy by promoting or inhibiting complement-dependent cytotoxicity and antibody-dependent cellular cytotoxicity. Furthermore, DAC HYP is being developed for subcutaneous administration (once every 4 weeks) in contrast to intravenous administration of Zenapax. Therefore, DAC HYP, which was jointly developed by Biogen Idec (Cambridge, MA) and Abbott Biotherapeutics Corporation (Redwood City, CA), and is currently in phase III clinical testing for MS, requires a new pre-clinical and clinical development program and is not yet commercially available.

We will summarize safety and efficacy data on daclizumab that collectively emerged from all studies after a detailed explanation of MOA of daclizumab.

\section{MOA of Daclizumab on the Human Immune System}

In regard to the MOA of daclizumab, studies in MS significantly expanded previous knowledge and demonstrated that the original assumptions, representing the rationale for development of daclizumab as a selective immunosuppressive agent against effector $\mathrm{T}$ cells, were not entirely correct.

First, the idea that IL-2 simply promotes T-cell immunity in vivo was challenged by the observations that mice with genetic deletions of IL-2 or its signaling chains (CD25, CD122) have apparently normal immune responses to selected pathogens, but instead succumb to severe lymphoproliferation and autoimmunity [25-29]. Subsequent studies revealed a nonredundant role of IL-2 signaling in the biology of FoxP3 + T-regs [10, 30-33], and an important role of high affinity IL-2 signaling in apoptosis (i.e.. cytokinewithdrawal cell death and activation-induced cell death) of effector $\mathrm{T}$ cells $[34,35]$. These studies provided a mechanistic explanation for the T-cell expansion and autoimmunity observed in IL-2 signaling deficient mice and highlighted a crucial role of IL-2 in immunoregulation. Intriguingly, this important contribution of IL-2 to the regulation of the immune responses has been confirmed by genetic linkage of IL-2 and/ or its signaling components (e.g., CD25, CD122) with several human autoimmune diseases, including MS [36-38].

However, humans with genetic deletion of CD25 also have severe immunodeficiency, in addition to lymphoproliferation and autoimmunity [39-41]. This observation 
indicates that the role of IL-2 in human immunity is highly complex and consists of both immune-stimulatory and immune-regulatory properties.

In our original MOA studies, although we attempted to confirm direct inhibitory effect of daclizumab on activated $\mathrm{T}$ cells, to our great surprise, we observed no inhibition of Tcell proliferation or their production of cytokines when $\mathrm{T}$ cells were isolated and polyclonally stimulated in the presence of in vivo achievable concentrations of daclizumab [42]. In contrast, our studies demonstrated that numbers of T-regs, their in vivo proliferation and in vitro suppressive functions toward effector $\mathrm{T}$ cells are all significantly inhibited by daclizumab therapy [13, 43]. Furthermore, daclizumab inhibited apoptosis of effector $\mathrm{T}$ cells in vivo [44] and in vitro [45], consistent with the elimination of proapoptotic effects of high-affinity IL-2 signaling defined in animal studies [34, 35]. Collectively, these mechanistic studies were exceedingly perplexing, because they predicted that the net effect of daclizumab therapy should be activation of $\mathrm{T}$ cell immunity, as was observed in CD25 KO animals and humans with genetic deletion of CD25. However, clinical trials clearly demonstrated that MS disease activity is inhibited by daclizumab therapy. This apparent discrepancy suggested that daclizumab had to have additional effects on the human immune system.

The first evidence that supported this hypothesis stemmed from a serendipitous observation that emerged from ex vivo immunophenotyping studies performed in conjunction with the first trial of daclizumab in MS [18]; we noticed remarkable expansion of lymphocytic cells that did not express TCR or Bcell receptor, but instead had high expression of CD122 (IL$2 \mathrm{R} \beta$ ) and intermediate expression of $\mathrm{CD} 8 \alpha$. A literature search indicated that these cells were most like the natural killer (NK) cells, which represent an important component of the innate immune response against viruses and tumors [46, 47]. Consequently, in the extension of the first trial of daclizumab in MS, we not only confirmed that expanding cells represent NK cells, but also observed that daclizumab therapy selectively expands only minor populations of blood NK cells, characterized by a high expression of CD56 surface marker [42]. These CD56 ${ }^{\text {bright }} \mathrm{NK}$ cells have been labeled as "immunoregulatory" [48, 49] for several reasons: 1$)$ they are selectively expanded during pregnancy, especially in the first trimester, and it is believed that they participate in mediating tolerance of the mother's immune system to the genetically foreign fetus $[50,51]$; 2) CD56 $6^{\text {bright }} \mathrm{NK}$ cells have, in comparison to the more prevalent CD56 ${ }^{\mathrm{dim}} \mathrm{NK}$ cells, lower levels of perforin, and they entirely lack granzyme $\mathrm{B}$, and were therefore, for a long time, considered noncytotoxic [52]; and 3) CD56 $6^{\text {bright }} \mathrm{NK}$ cells are enriched in lymph nodes [53] and can secrete large levels of cytokines early in the immune response [54], so it was suggested that they may alter the phenotype of newly activated T cells during the T-cell priming process. However, the direct evidence for their immunoregulatory role was lacking. The analysis of their function was limited due to their low frequencies in the peripheral blood (i.e., $5-10 \%$ of NK cells, which represent approximately $1 \%$ of lymphocytes), and the lack of an analogous cell type in the NK cells of rodents that lack the CD56 marker. Because daclizumab expanded numbers of CD56 $6^{\text {bright }}$ NK cells in the peripheral blood to up to $500 \%$ [20, 42], daclizumab-treated MS patients provided a unique opportunity to study the immunoregulatory functions of these cells in detail.

First, we observed that while daclizumab had no effect on expansion or cytokine production of polyclonally activated $\mathrm{T}$ cells in the absence of NK cells, when NK cells were present during T-cell activation, survival of activated $\mathrm{T}$ cells was severely limited. Subsequent mechanistic studies demonstrated that this phenomenon was due to NK-cell mediated cytotoxicity toward activated autologous T cells [42]. This interpretation contradicted the well-accepted dogma in immunology, which stipulated that NK cells do not kill autologous cells that have normal expression of major histocompatibility complex class I (MHC-I) molecules, because killer inhibitory receptors expressed on the surface of NK cells provided inhibitory signal after their interaction with self-MHC-I molecules [55]. However, CD56 ${ }^{\text {bright }}$ NK cells lack inhibitory killer inhibitory receptors and instead use CD94/NKG2A heterodimer, which recognizes histocompatibility antigen, alpha chain E (HLA-E) expression on target cells as their main inhibitory receptor [56]. Because HLA-E binds lead peptides from self-MHC-I molecules, which stabilize expression of HLA-E on the cell surface, when MHC-I molecules are downmodulated (e.g., in cancer or virally infected cells), then the expression of HLA-E molecules is also expected to decline. Therefore, this system monitors MHC-I expression on target cells only indirectly (as compared to direct killer inhibitory receptor/MHC-I interaction characteristic of $\mathrm{CD} 56^{\mathrm{dim}} \mathrm{NK}$ cells). We not only demonstrated that killing of activated autologous $\mathrm{T}$ cells is mediated predominantly by $\mathrm{CD} 56^{\text {bright }} \mathrm{NK}$ cells [42], but later we also dissected the molecular mechanisms of this killing [57].

Specifically, we demonstrated that CD56 $6^{\text {bright }}$ NK cells kill autologous activated $\mathrm{T}$ cells via perforin-mediate degranulation, which induces reactive oxygen species and loss of mitochondrial transmembrane potential in the target cells. This represents the characteristic signature of killing by 2 closely related granzymes (i.e., granzyme A [Gz]A and GzK) [58]. This was highly interesting, as CD56 $6^{\text {bright }} \mathrm{NK}$ cells are the only immune cells that express GzK constitutively [59]. Although selective blockers of GzK do not currently exist, we observed that inhibition of GzK expression by small interfering RNA technology significantly inhibited killing of syngeneic activated T cells by the NK92 cell line, which originates from and retains functional characteristics of CD56 $6^{\text {bright }}$ NK cells $[57,60]$. Finally, 
going back to cryopreserved samples from daclizumabtreated MS patients, we observed that daclizumab therapy specifically enhanced expression of GzK, but not the 2 traditionally studied and more widely expressed granzymes (GzA and GzB [57]. The observation of a strong correlation between expansion of $\mathrm{CD} 56^{\text {bright }} \mathrm{NK}$ cells and contraction of absolute numbers of CD4+ and CD8+ T cells induced by daclizumab therapy provided in vivo support for the NK-mediated cytotoxicity toward activated autologous $\mathrm{T}$ cells [42].

Thus, we conclude that CD56 $6^{\text {bright }}$ NK cells use GzK (and possibly also related GzA) to kill autologous activated $\mathrm{T}$ cells, and this immunoregulatory function is greatly enhanced by daclizumab therapy through activation and expansion of $\mathrm{CD} 56^{\text {bright }} \mathrm{NK}$ cells and their upregulation of GzK expression. Because this type of cytotoxicity can be inhibited by strong, cell-permeable antioxidants, our data raise a voice of caution for indiscriminate use of antioxidants in subjects with inflammatory MS without proper evaluation in the clinical trial setting.

The final question was where does the killing of activated autologous T cells happen in vivo? It was shown previously that $\mathrm{CD} 56^{\text {bright }} \mathrm{NK}$ cells are enriched at inflammatory sites [61], but there were no studies that investigated the access of these rare cells to the intrathecal compartment. Because in the MS disease process the ability of CD56 ${ }^{\text {bright }} \mathrm{NK}$ cells to kill autologous activated $\mathrm{T}$ cells would be most relevant in the CNS, we asked if CD56 $6^{\text {bright }} \mathrm{NK}$ cells could be detected in the cerebrospinal fluid (CSF) of MS patients and whether their numbers in the CSF are expanded after administration of daclizumab. Indeed, we found that CD56 $6^{\text {bright }} \mathrm{NK}$ cells are relatively enriched in the CSF as compared to blood and their CSF levels significantly increased 6.5 months after initiation of daclizumab treatment [22]. Intriguingly, this study also demonstrated that CD25 Tac epitope (i.e., the target of daclizumab therapy) was completely blocked, not only in the blood, but also in the CSF after daclizumab treatment. Experimental evidence indicates that only $0.1 \%$ of blood concentrations of therapeutic $\mathrm{mAb}$ gain access to the CSF when the blood brain barrier is intact [62]. This would correspond to a peak concentration of $10 \mathrm{ng} / \mathrm{ml}$ of daclizumab in the CSF, which is approximately 100-fold lower in concentration compared to that required for the saturation of CD25 expression on all $\mathrm{T}$ cells. Therefore, if $\mathrm{T}$ cells were re-activated in the CNS, available concentrations of daclizumab would be insufficient to saturate de novo produced $\mathrm{CD} 25$. As a result, we had to conclude that the cells detected in the CSF acquired blockade of CD25 Tac epitope in the blood and were not reactivated in the CNS compartment [22]. This means that either the inflammatory process was abrogated, or alternatively the $\mathrm{T}$ cells that became activated in CNS tissue during daclizumab therapy were either killed by $\mathrm{CD} 56^{\text {bright }} \mathrm{NK}$ cells or did not migrate out of the CNS tissue back to the CSF compartment. As further supporting evidence for inhibition of the intrathecal inflammatory process in daclizumab-treated MS patients, we observed that 6.5 months after the initiation of daclizumab, CSF levels of cytokine IL-12p40 [22] and chemokine CXCL13 [63], both of which are produced by activated macrophages, microglia, and dendritic cells (DCs), were decreased by 50 to $60 \%$.

We also addressed the question of why CD $56^{\text {bright }} \mathrm{NK}$ cells are expanded and activated by daclizumab therapy. Interestingly, CD56 $6^{\text {bright }} \mathrm{NK}$ cells, in contrast to CD56 $6^{\text {dim }}$ NK cells, express some CD25 on their cell surface [42, 49] and are selectively expanded in vivo in response to the administration of limiting doses of IL-2 [64]. This phenomenon has been interpreted as evidence that CD56 ${ }^{\text {bright }} \mathrm{NK}$ cells receive an IL-2 signal via high-affinity IL-2R, whereas CD56 ${ }^{\mathrm{dim}} \mathrm{NK}$ cells, which lack CD25, can signal only via an intermediate-affinity IL-2R. However, because daclizumab therapy abrogates formation of high-affinity IL-2R, if CD25 expression was the only difference between $\mathrm{CD} 56^{\text {bright }}$ and CD56 ${ }^{\mathrm{dim}} \mathrm{NK}$ cells, then daclizumab therapy should have inhibited, rather than expanded CD56 $6^{\text {bright }}$ NK cells. There is another striking difference between these NK cell subsets, however, and that is the expression of IL-2R $\beta$ (CD122), which is at least 10 -fold higher on $\mathrm{CD} 56^{\text {bright }}$ as compared to $\mathrm{CD} 56^{\mathrm{dim}} \mathrm{NK}$ cells, and 100-to 1000 -fold higher compared to resting $\mathrm{T}$ cells [42]. As a consequence, CD56 ${ }^{\text {bright }}$ NK cells have the highest expression of intermediateaffinity IL-2R among all accessible human immune cells. We hypothesized, and experimentally confirmed, that this high expression of intermediate-affinity IL-2R allows CD56 ${ }^{\text {bright }} \mathrm{NK}$ cells to sustain their IL-2 signaling in the presence of daclizumab [13]. Furthermore, as daclizumab limits consumption of IL-2 by T cells, which are dependent on high-affinity IL-2R because of their limited expression of CD122, excess IL-2 can be used by CD56 $6^{\text {bright }}$ NK cells for signaling via the intermediate affinity IL-2R, which is not being inhibited by daclizumab. Thus, paradoxically, daclizumab therapy expands and activates CD $56^{\text {bright }} \mathrm{NK}$ cells in an IL-2-dependent manner [13].

We observed a strong correlation between in vivo expansion of $\mathrm{CD} 56^{\text {bright }} \mathrm{NK}$ cells and inhibition of focal brain inflammatory activity measured by CEL [42], suggesting that immunoregulation of T-cell responses by $\mathrm{CD} 56^{\text {bright }} \mathrm{NK}$ cells may represent a decisive MOA of daclizumab in MS. This observation indicated that the level of expansion of CD $56^{\text {bright }}$ NK cells and the decrease in ratios of T cells (as target cells) to CD56 ${ }^{\text {bright }} \mathrm{NK}$ cells (as effector cells) could represent a useful biomarker indicative of therapeutic response to daclizumab therapy, as it differentiated full responders from partial responders in our MS cohort [20]. These data have been reproduced in 2 independent multicenter phase II trials of daclizumab in MS: CHOICE [23] and SELECT trials [65]. 
A

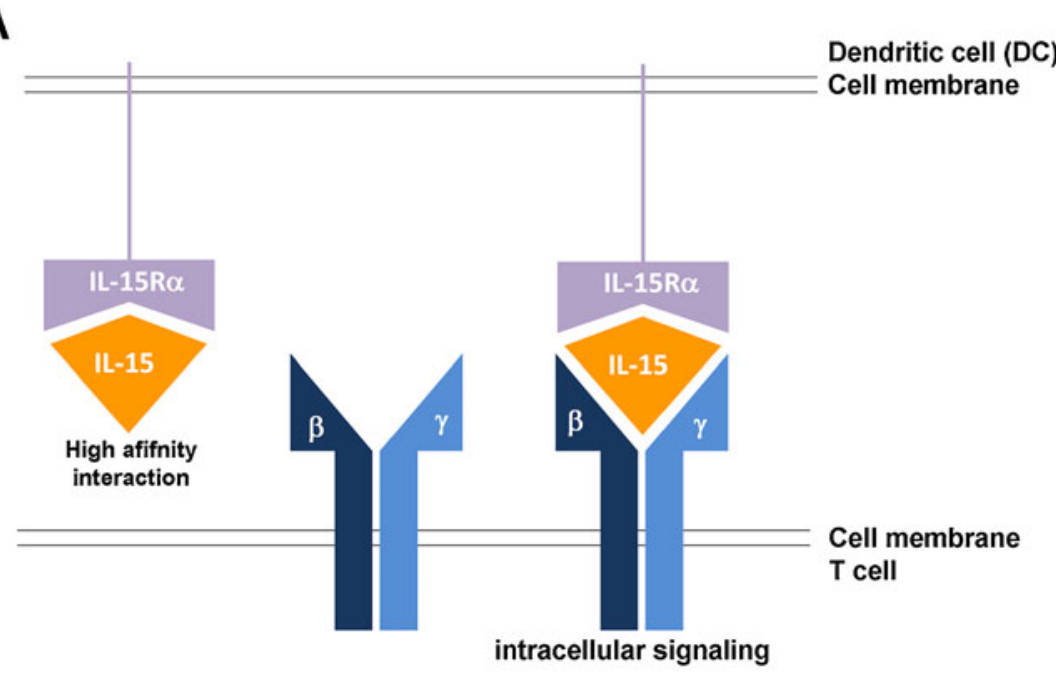

Dendritic cell (DC)

B
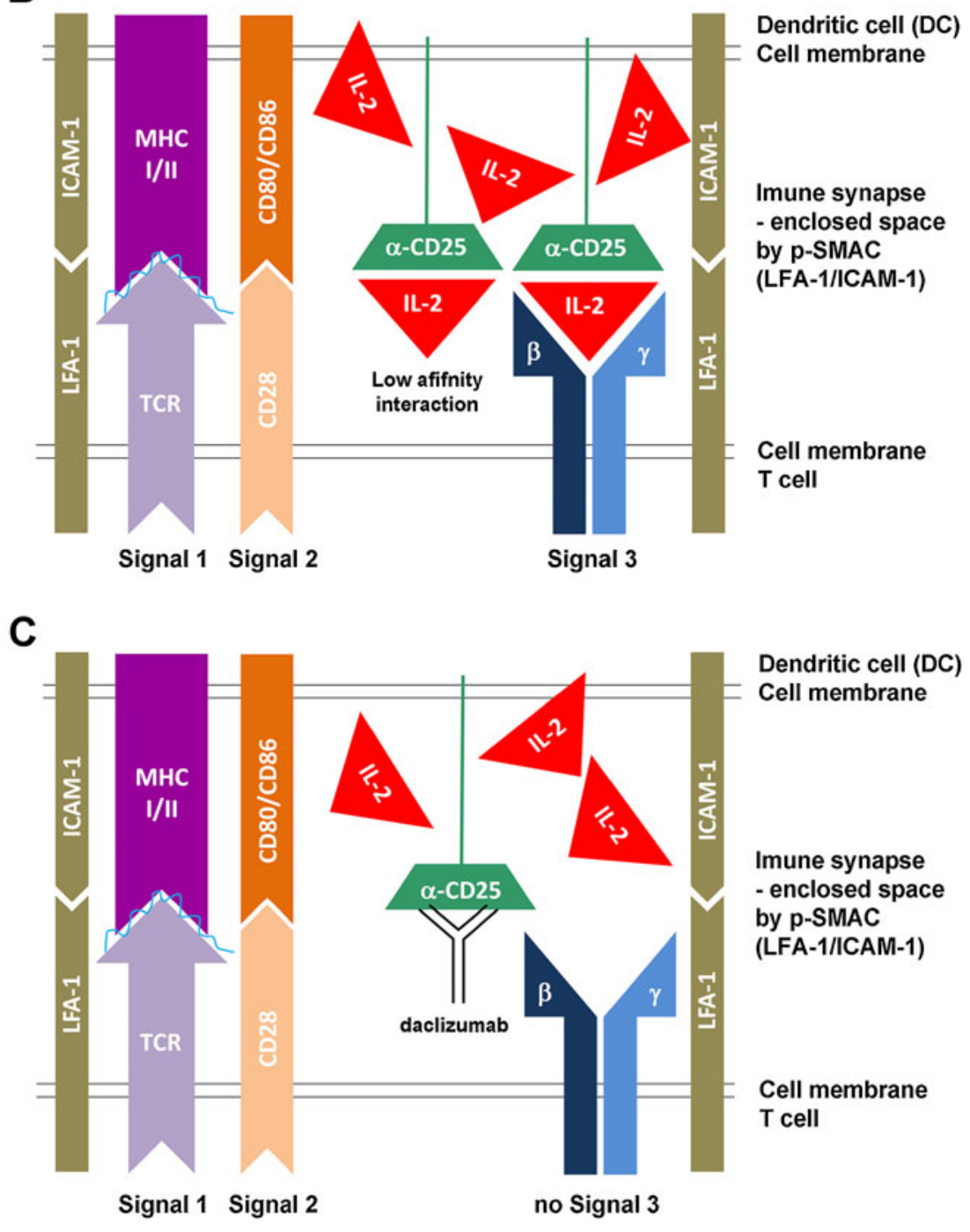
Fig. 2 Trans-presentation of interleukin (IL)-15 and IL-2. a Because of very high affinity between interleukin-15 receptors alpha (IL-15R $\alpha$ ) chain and IL-15, IL-15R $\alpha$ chain can easily capture and hold released IL-15. This IL-15R $\alpha /$ IL-15 complex can be then easily trans-presented to intermediate-affinity IL-2/IL-15 receptor, expressed on T cells or NK cells. b In contrast, CD25 (IL-2R $\alpha$ chain) has only low affinity for IL-2, so it is highly unlikely that CD25 would be able to effectively capture small concentrations of IL-2 and create stable CD25/IL-2 complexes for trans-presentation, if IL-2 can easily diffuse to the environment. However, if instead the IL-2 is released into the synaptic cleft, which represents an enclosed space between the peripheral supramolecular activation cluster (p-SMAC) formed by adhesion molecules, such as lymphocyte function associated antigen-1 (LFA-1) and intercellular adhesion molecule-1 (ICAM-1), then its diffusion is limited and high IL-2 concentrations can be achieved. Under those circumstances, CD25 expressed on the surface of the dentritic cells (DC), which formed stable immune synapse (IS) with antigen-specific T cell, can effectively capture released IL-2 and trans-present it to the T cell at the time when $\mathrm{T}$ cell does not yet express CD25. This cytokine signal (signal 3), delivered concomitantly with the signal 1, provided by Tcell receptor (TCR), specifically recognizing peptide loaded on the major histocompatibility complex (MHC) and the co-stimulatory signal 2 (e.g., provided by interaction of CD28 with CD80 or CD86) seems to be necessary for efficient activation of human T cells. $\mathbf{c}$ When $\mathrm{CD} 25$ on the DC is blocked by daclizumab, then primed $\mathrm{T}$ cell cannot receive IL-2 signal (signal 3) concomitantly with its signal 1 and 2, resulting in suboptimal stimulation of $\mathrm{T}$ cell. The functional consequences are inhibition of antigen-specific $\mathrm{T}$ cell activation, formation of antigen-specific effector and memory $\mathrm{T}$ cells

Since our original description of CD56 $6^{\text {bright }} \mathrm{NK}$ cells as an immunoregulatory population relevant to the MS disease process [42], expansion of these cells was observed by other effective therapies for MS, such as IFN- $\beta[20,66]$ and rituximab [67]. Furthermore, unbiased cytometric profiling in MS uncovered a deficiency in non-T, non-B-cell lymphocytes that expressed the CD $8 \alpha$ surface marker as the only distinguishing feature between MS subjects and controls [68]. It is highly probable, that these cells represent a subpopulation of CD $56^{\text {bright }} \mathrm{NK}$ cells. Functional deficiencies in NK cells, especially in their secretion of IFN- $\gamma$, which is mainly secreted by CD56 $6^{\text {bright }}$ NK cells, have been associated with MS and other autoimmune diseases by many studies performed in the past 30 years [69-71]. It is likely that $\mathrm{CD} 56^{\text {bright }} \mathrm{NK}$ cells work together with other regulatory cell populations, such as FoxP3+ T-regs or Tr1 regulatory cells, to maintain immune tolerance under physiological conditions. Whether any of these regulatory cells play a more important role in specific immune-mediated disorders remains an open question.

The strong correlation between daclizumab-driven expansion of CD56 ${ }^{\text {bright }} \mathrm{NK}$ cells and inhibition of the MS disease process suggested that this is the main or potentially the only MOA responsible for beneficial effect of daclizumab in MS. However, in our extensive experience with daclizumab therapy, we identified a patient who did not expand CD56 $6^{\text {bright }}$ NK cells at all, but still experienced more than $80 \%$ suppression of CEL and stabilization of clinical disability. This patient taught us there had to be another MOA, unrelated to $\mathrm{CD} 56^{\text {bright }}$ NK cells.

We started our search by focusing on myeloid DCs, because these cells upregulate CD25 with their activation by microbial stimuli and are also endowed with the ability to synthesize and secrete IL-2 [72]. Because mature dendritic cells (mDCs) are the most important antigen presenting cells that activate $\mathrm{T}$ cells in an antigen-specific manner, we asked if daclizumab affects this crucial function of mDCs. Indeed, we observed that peak in vivo achievable concentrations of daclizumab $(10 \mu \mathrm{g} / \mathrm{ml})$, which had no discernable effect on proliferation of polyclonally activated $\mathrm{T}$ cells, almost completely abolished expansion of the antigen-specific $\mathrm{T}$ cells activated by $\mathrm{mDCs}$ [45]. Using selective pre-treatment of $\mathrm{mDCs}$ or $\mathrm{T}$ cells with daclizumab, small interfering RNA technology and ultimately also $\mathrm{T}$ cells derived from a rare human subject with genetic deletion of $\mathrm{CD} 25$, we convincingly demonstrated that it is the blockade of CD25 on mDCs (and not on T cells) that underlies this inhibition. We then hypothesized that mDCs are activated by the IL-2 signal and that this activation is necessary for effective priming of antigen-specific $\mathrm{T}$ cells. However, this hypothesis turned out to be incorrect, because myeloid DCs, whether in the resting or activated state, do not express CD122, and therefore cannot receive an IL-2 (or IL-15) signal [45, 73].

As a result, we pursued the alternative hypothesis, that mDCs use their CD25 to present IL-2 to primed T cells "in trans," in a manner analogous to what was previously described for IL-15 [74] (Fig. 2a). In other words, mDCs use their CD25 in trans to complement intermediate affinity IL-2R on resting $T$ cells, and thus allow $T$ cells to receive a high-affinity IL-2R signal at a time when $T$ cells express only intermediate-affinity IL-2R. The only problem with this hypothesis was the discrepancy in affinities of IL$15 \mathrm{R} \alpha$ versus $\mathrm{IL}-2 \mathrm{R} \alpha$ (i.e., CD25) for their respective ligands; whereas IL-15R $\alpha$ has a very strong affinity for IL-15, such that the majority (if not all) of IL-15 is bound to IL-15R $\alpha$ in vivo (Fig. 2a), CD25 has a very low affinity for IL-2, which allows it to bind IL-2 only under circumstances of IL-2 abundance. Thus, it is highly unlikely that CD25 would be able to effectively capture small quantities of IL-2 secreted by mDC, when IL-2 can freely diffuse to the environment. We conceptually solved this dilemma by hypothesizing that trans-presentation of IL-2 by mDCs occurs across the immune synapse (IS) (Fig. 2b). Therefore, instead of indiscriminative release of IL-2 to the environment, we hypothesized that mDCs release their IL-2 into the small synaptic cleft formed between an $\mathrm{mDC}$ and an antigen-specific $\mathrm{T}$ cell, and that this physical constraint 
limits the diffusion of IL-2 away from the primed T cell. Consequently, sufficiently high concentrations of IL-2 are reached in the IS to allow effective capture of IL- 2 by CD25 expressed on $\mathrm{mDC}$ and subsequent trans-presentation of IL2 to the primed, antigen-specific $\mathrm{T}$ cell.

This hypothesis was fully supported by our subsequent mechanistic studies; first we observed that trans-presentation of IL-2 by CD25-expressing $\mathrm{mDC}$ to $\mathrm{CD} 25$ negative T cells was extremely inefficient when the T cells did not carry a TCR specific for the antigen being presented by the $\mathrm{mDC}$ (i.e., when the stable IS was not formed between the $\mathrm{mDC}$ and the T cell). This was true even when we added IL-2 exogenously to such $\mathrm{mDC}-\mathrm{T}$ cell co-cultures. In contrast, when CD25-negative $\mathrm{T}$ cells were specific for the antigen presented by $\mathrm{mDC}$, they promptly received strong IL-2 signal without any exogenous addition of IL-2, and this IL-2 signaling was significantly reduced if $\mathrm{mDCs}$ were pre-treated with daclizumab [45] (Fig. 2c). We also observed that CD25, expressed solely on mDCs, co-localized to the IS with the antigenspecific $\mathrm{T}$ cell, and that it was only the $\mathrm{T}$ cell, and not the $\mathrm{mDC}$, that received the IL-2 signal, as measured by phosphorylated STAT5 molecules. The reason $\mathrm{mDC}$-mediated IL-2 signaling on $\mathrm{T}$ cells occurred strictly in an antigen-specific manner was the fact that only when mDCs were co-cultured with $\mathrm{T}$ cells that recognized their antigen-MHC-II complex, then $\mathrm{mDCs}$ would release their IL-2. Therefore, there is almost certainly bilateral communication required between $\mathrm{mDC}$ and $\mathrm{T}$ cell (likely triggered by cognate TCR/antigen-MHC interaction, called "Signal 1") (Fig. 2b, c) before the $\mathrm{mDC}$ decides to release its IL-2 to the synaptic cleft. This assures that limiting amounts of IL-2 produced at the very beginning of the immune response are not wasted for "bystander" $T$ cells, but are instead delivered specifically to $\mathrm{T}$ cells that have received full TCR and co-stimulatory signals (Signal 2) (Fig. 2b, c), and can thus mediate an effective immune response. In our in vitro assays, signal 3 , provided by $\mathrm{mDC}$ derived IL-2, was absolutely necessary for efficient expansion of antigen-specific $\mathrm{T}$ cells, and when it was abrogated (by blocking CD25 on mDCs), T cells proliferated poorly, despite the fact that daclizumab-pretreated $\mathrm{mDCs}$ expressed high levels of MHC-peptide and high levels of co-stimulatory molecules. This observation is fully consistent with immunodeficiency observed in children with a genetic deletion of CD25. Of note, $\mathrm{T}$ cells could enter the proliferation cycle if we supplemented in vitro conditions with IL-7 as an alternative source of $\gamma_{\mathrm{c}}$-signaling cytokine. However, $\mathrm{T}$ cells expanded this way did not express full effector functions, as did T cells that received IL-2 signal during priming. A similar observation was made in the animal system, in which IL-2 signal was absolutely necessary during the priming of antigen-specific $\mathrm{CD} 8+\mathrm{T}$ cells for effective development of T-cell memory responses [75]. Again, these observations are fully compatible with the bizarre combination of immunodeficiency and lymphoproliferation that is the characteristic phenotype of individuals with a genetic deletion of CD25.

Interestingly, for this MOA to occur, daclizumab has to saturate CD25 in sites in which the antigen-presentation happens, such as lymphoid organs [76] and inflamed tissues. Because concentrations of intravenously administered $\mathrm{mAb}$ are expected to be higher in the blood than in tissues, this requirement may explain the previously mentioned paradoxical observations that efficacy of daclizumab decreases 4 to 6 weeks after the last intravenous dose, despite the fact that the CD25 epitope remains almost completely saturated ( $>95 \%$ ) in the blood [18]. Analogously, this requirement may also explain why higher doses of daclizumab $(2 \mathrm{mg} / \mathrm{kg})$ enhanced therapeutic efficacy in patients with a suboptimal response to $1 \mathrm{mg} / \mathrm{kg}$ dosing, despite the fact that this classical dosing regimen completely saturated the CD25 epitope in the periphery [20].

Final-described MOA represents inhibitory effect of daclizumab on innate lymphoid cells (ILCs), especially on development of their pro-inflammatory subtype called lymphoid tissue inducer (LTi) cells [63]. As in the case of CD56 $6^{\text {bright }} \mathrm{NK}$ cells, it was broader immunophenotyping associated with the NIH daclizumab trial (the Investigating Mechanism of Action of DAC HYP in the Treatment of High-Inflammatory Multiple Sclerosis (MS); Clinicaltrials.gov identifier: NCT01143441) that alerted us to the link between LTi cells and daclizumab therapy [63].

ILCs are a heterogeneous group of lymphocytes that belong to innate, rather than adaptive immune systems. Although NK cells are the most familiar subset of ILCs, this category also contains relatively recently described cells with constitutive expression of retinoic acid receptor-related orphan receptor gamma-t. Depending on the tissue from which these cells have been isolated, they express a slightly different phenotype and have been labeled by different names [77, 78], such as LTi cells, ILC22 (i.e., IL-22producing ILCs, which also express NKp44) and ILC17 (IL-17 producing ILCs). It is clear that these different ILC categories are developmentally related, as they all originate from CD34+ hematopoietic precursors and are all dependent on transcriptional regulator Id2 [79].

Although LTi cells play a fundamental role in the formation of secondary lymphoid tissues during fetal development [80], tertiary ectopic follicles associated with chronic inflammation can form in retinoic acid receptor-related orphan receptor gamma-t-deficient animals [81], in which either activated $\mathrm{T}$ cells or B cells can acquire a lymphoid tissue-inducing capacity. Therefore, the role of adult LTi cells remains unclear. Nevertheless, it has been hypothesized that through their constitutive expression of OX40 and CD30, adult LTi cells may play a vital role in the evolution and maintenance of CD4 + T-cell memory [82] and related B-cell/antibody responses, including formation of high-affinity class-switched IgG [83]. 
We observed that untreated MS patients have significantly higher levels of circulating LTi cells in comparison to healthy controls. On the other hand, daclizumab therapy normalizes this abnormality, by skewing development of CD34+ hematopoietic stem cells and c-kit+undifferentiated ILC precursors away from LTi lineage and toward CD $56^{\text {bright }}$ NK cells, by enhancing IL-2 signaling through intermediateaffinity IL-2R [63].

Although we cannot directly visualize or quantify meningeal lymphoid follicles in living MS subjects [84, 85], we observed that daclizumab therapy decreased intrathecal production of chemokine CXCL13 and of IgG, measured as the $\operatorname{IgG}$ index [63]. Intriguingly, the effect of daclizumab on IgG production was specific for the intrathecal compartment, because we reported in previous studies that daclizumab did not lower blood levels of IgG, IgA, or IgM [18, 42]. Because daclizumab does not limit migration of immune cells to the intrathecal compartment [22], decrease in intrathecal levels of CXCL13, which is highly expressed in tertiary lymphoid follicles $[85,86]$, indirectly supports the notion that inhibition of LTi cells by daclizumab may have impeded the maintenance of meningeal lymphoid aggregates and associated immune memory responses. Because the formation of meningeal lymphoid follicles in MS has been associated with greater pathology of the underlying gray matter [84], future studies should investigate whether long-term administration of daclizumab inhibits atrophy of the CNS gray matter that is in direct contact with the CSF/meningeal compartment.

\section{MOA of Daclizumab: Unanswered Questions and Ongoing Studies}

It appears that daclizumab has even broader immunomodulatory effects than those published so far. Additional changes in the immune system induced by daclizumab therapy are currently being pursued mechanistically, and it is likely that knowledge in regard to the MOA of daclizumab and the diverse effects of IL-2 on the human immune system will continue to grow.

A further complicating feature that was not described in detail in the current review (because it is not yet fully understood) is the effect of soluble cytokine receptor chains, in this case especially soluble CD25 (sCD25), but also soluble CD122 (sCD122), on IL-2 signaling. It is known that both activated $\mathrm{T}$ cells, and especially pathogen-activated monocytes and macrophages secrete large amounts of sCD25 [87, 88 ], and that sCD25 competes with surface CD25, and therefore inhibits high-affinity IL-2 signaling [89]. Thus, sCD25, to some extent, mimics daclizumab by skewing IL-2 signaling from high affinity toward intermediate affinity, and based on our data [45], 1 can predict that SCD25 would enhance T-cell survival, leading to more efficient expansion of activated $\mathrm{T}$ cells. This was indeed observed experimentally [89]. However, sCD25 cannot reproduce all effects of daclizumab (e.g., we would predict minimal effect of sCD25 on transpresentation of IL- 2 by $\mathrm{mDC}$, because $\mathrm{sCD} 25$ would likely diffuse away from cells and therefore become mostly excluded from the small synaptic cleft formed between $\mathrm{mDC}$ and primed T cell). Therefore, the net effect of $\mathrm{sCD} 25$ would cause stimulation of the adaptive immune responses. Because secretion of $\mathrm{sCD} 25$ by monocytes and macrophages is linked to their stimulation by pathogens, $\mathrm{SCD} 25$ may represent a unique feedback mechanism that links continuous activation of adaptive immune responses in the infected tissue to the persistence of pathogen. Clearly, more work needs to be done to support this hypothesis with experimental evidence.

When multiple different effects on the immune system are described, the question often asked is which of these MOA is the most important for the observed therapeutic effect? Because these various effects cannot be separated from each other in vivo, it is virtually impossible to answer this question within the context of 1 particular therapy. Instead, if the same mechanism is being targeted by another successful therapy (e.g., expansion of CD $56^{\text {bright }} \mathrm{NK}$ cells by IFN- $\beta$ ), then the likelihood that the described mechanism is important for studying disease process increases. Similarly, correcting abnormality that is associated with the disease state (e.g., the ability of daclizumab to normalize increased numbers of circulating LTi cells in MS subjects) provides support to the notion that the observed MOA may be pathophysiologically relevant. Therefore, it is only the aggregate experience with different therapies that may elucidate the most important pathophysiological drivers of the disease that consequently lead to the knowledge that is necessary for design of more targeted therapies.

At the same time, however, we should not be expecting only 1 decisive MOA linked to 1 therapeutic modality. The experience with immunomodulatory monoclonal antibodies, which by definition target only 1 specific molecule and yet exert multiple in vivo effects, provide clear evidence that pleiotropy of functions, often dependent on situational diversity, is inherent to biological systems. Such pleiotropy and functional redundancies make biological systems robust and resilient [90]. Reflecting on newly discovered intricacies of how a single cytokine can have profound and at times opposing effects on multiple cells of the immune system, based on the dynamics of expression of its signaling chains and competition for available cytokines (both of which are intimately linked to spatio-temporal characteristics of the developing immune response), 1 can only admire the ingenuity and organizational nondualism of the immune system. For this reason, it is very likely that multiple, if not all described MOA of daclizumab are important on the population level. That does not eliminate the 
possibility that occasional patients, likely due to their genetic background, may not be able to utilize all MOAs [45], and may therefore rely more prominently on the remaining ones, or experience suboptimal therapeutic response.

\section{Efficacy and Safety of Daclizumab Therapy in MS}

We already mentioned that all open label baseline-versus-treatment studies demonstrated that intravenously administered daclizumab ( $1 \mathrm{mg} / \mathrm{kg}$ every 4 weeks) inhibited CEL on brain MRI by more than $75 \%$, regardless of whether daclizumab was administered as monotherapy or as an add-on to IFN- $\beta$ [18-22]. This was associated with stabilization $[18,19,21]$ or even improvements [20,22] of clinical outcome measures. Clearly, limited selection of highly active MS subjects and open-label design without placebo control were major drawbacks of these early studies [91, 92], although the consistent efficacy on objective outcome measures, such as CEL or MSFC provided a strong impetus for commercial development of daclizumab for the treatment of inflammatory MS.

In the first industry-sponsored, placebo-controlled trial (CHOICE study, N=230; the Study of Subcutaneous Daclizumab in Patients With Active, Relapsing Forms of Multiple Sclerosis; Clinicaltrials.gov identifier: NCT00 109161), addition of subcutaneously administered daclizumab (low-dose: $1 \mathrm{mg} / \mathrm{kg}$ every 4 weeks and high- dose: $2 \mathrm{mg} / \mathrm{kg}$ every 2 weeks) to IFN- $\beta$, decreased CEL lesion by $72 \%$ in the high-dose arm $(p=0.004)$, and by $25 \%(p=$ $0.51)$ in the low-dose arm [23]. The high-dose arm yielded systemic levels of daclizumab comparable to the intravenous $1 \mathrm{mg} / \mathrm{kg}$ dose, which was used in all previous open-label trials. In the phase IIb SELECT trial (Safety and Efficacy Study of Daclizumab HYP to Treat Relapsing-Remitting Multiple Sclerosis [SELECT]; N=600; Clinicaltrials.gov identifier: NCT00390221), 2 doses of DAC HYP monotherapy (150 mg or $300 \mathrm{mg}$ every 4 weeks) administered subcutaneously for 1 year were compared to a placebo. Both doses of daclizumab inhibited formation of CEL (by $68.8 \%$ and $79.2 \% ; p<0.001$ ) and new or enlarging T2 lesions (by $70.4 \%$ and $79.0 \% ; p<0.001)$ on brain MRI [93]. This efficacy on MRI parameters of MS lesion formation was paralleled by significant inhibition of annualized relapse rate (by $54.3 \%$ and $50 \% ; p<0.001)$ and by inhibition of disability progression (by $57 \%$; $p=0.021$ for $150 \mathrm{mg}$ dose and by $43 \%$; $p=0.091$ for $300 \mathrm{mg}$ dose). Clearly, these efficacy data compare very favorably with current Food and Drug Administration-approved therapies, but they need to be reproduced in phase III trials.

In general, daclizumab therapy has been very well tolerated. The overall incidence of adverse events (AE) and the rate of discontinuation of therapy were similar between the placebo and daclizumab arms in both the CHOICE [23] and SELECT [93] trials. The most common AEs observed in MS trials of daclizumab belong to 4 categories: 1) skin rashes, 2) lymphadenopathy, 3) elevation of liver function tests (LFTs), and 4) infections [18, 20, 22, 23, 93].

We will discuss these categories of $\mathrm{AE}$ in view of the described MOA Skin rashes were seen in $13 \%$ of daclizumab subjects and $8 \%$ of placebo subjects in the CHOICE study [23]. In NIH open-label trials, we observed frequent skin rashes, mostly of mild intensity that responded to emollients or topical steroids. We now advise patients to routinely use sunscreen and skin moisturizers, because we have observed an increased frequency of skin rashes on sunexposed areas and with dry, scaling skin. However, we have also observed few prolonged and more severe skin rashes, which required systemic steroids and/or discontinuation of therapy $[18,20,22]$. Serious coetaneous events were observed in $1 \%$ of DAC HYP-treated subjects in the SELECT trial [93]. It is not clear what underlies enhanced skin reactivity in daclizumab-treated subjects; there is 1 hypothesis that implicates daclizumab-driven inhibition of FoxP3 T-regs [43]. The mechanism underlying development of skin rashes with daclizumab therapy is being investigated in the ongoing open-label clinical trial at the NIH (Clinicaltrials.gov identifier: NCT01143441) that includes skin biopsies before and 1 year after administration of daclizumab.

Mild generalized lymphadenopathy is often associated with daclizumab therapy $[18,20]$ without any pathological consequences. We have evaluated several subjects with prominent or persistent lymphadenopathy using fine needle biopsy and found no pathological changes in flow cytometry or pathology profile (unpublished observations).

Elevations of LFTs have been observed in daclizumabtreated cohorts; whereas in the NIH trials we observed only transient elevation of LFTs that did not require discontinuation of therapy $[18,20,22]$, the SELECT trial reported elevations of LFTs (5 times greater than the upper limit of normal) in $4 \%$ of DAC HYP-treated subjects. Again, the mechanism behind this phenomenon is unclear, however, CD56 ${ }^{\text {bright }} \mathrm{NK}$ cells have been reported to be a prominent immune cell population in the liver under physiological conditions [94].

Although, in our open-label NIH studies, we observed a slight increase in the frequency of mild infectious $\mathrm{AE}$ (mostly urinary and upper respiratory tract infections), the placebo-controlled CHOICE study did not demonstrate an increased incidence of infections in the daclizumab arms [23]. In contrast, the SELECT trial reported an increase in serious infections $(2 \%)$ in the DAC HYP cohort. One DAC HYP-treated subject died 
due to a complications of psoas abscess [93]. However, no opportunistic infections were observed. Our MOA studies indicate that daclizumab-treated subjects may be susceptible to infections, especially with new pathogens, because of the inhibitory effect of daclizumab on T-cell priming. On the other hand, daclizumab does not limit access of immune cells to the intrathecal compartment and expanded $\mathrm{CD} 56^{\text {bright }} \mathrm{NK}$ cells may provide effective immunity against (herpes) viruses [47] and potentially also enhanced immuno-surveilance against cancer. This conclusion is supported by in vivo observations from experience in transplantation, in which transplant patients who received daclizumab (in addition to standard immunosuppressive therapy) had in fact lower levels of infectious complications, including CMV [95] and a lower level of secondary cancers [96] than those patients who received identical immunosuppression without daclizumab. Nevertheless, only long-term safety data on a large number of subjects will demonstrate whether daclizumab increases incidence of serious or opportunistic infections.

\section{Conclusions}

At the time we initiated studies of daclizumab in MS, the model of its MOA was based on the idea that IL-2 is a crucial T-cell growth factor and by blocking high-affinity IL-2 signaling on T cells, daclizumab would inhibit effector functions of activated T cells. Instead, carefully conducted in vivo observations supplemented by mechanistic in vitro studies revealed entirely unexpected effects of daclizumab on cells belonging to the innate immune system, CD56 $6^{\text {bright }}$ NK cells, mDCs, and ILCs. These effects were not previously identified in animals with genetically deleted IL-2 or its signaling components, signifying that carefully conducted mechanistic studies linked to human interventional trials have the potential to discover novel biological mechanisms. Such newly acquired insights may be relevant not only for the MOA of the studied therapeutic, but also for the pathophysiology of the targeted disease. The MOA of daclizumab also pinpoints that adaptive immune responses, which are dysregulated in autoimmunity, are tightly controlled by cells of the innate immune system. For that reason, both of these systems need to be studied in an integrated manner before we can fully understand mechanisms that lead to the breakdown of tolerance and development of chronic immunemediated pathology.

Acknowledgments This work was supported by the Intramural Research Program of the National Institute of Neurological Disorders and Stroke (NINDS). B.B. is a co-inventor of the National Institutes of Health patents related to daclizumab therapy, and as such has received patent royalty payments.
Required Author Forms Disclosure forms provided by the authors are available with the online version of this article.

\section{References}

1. Ruscetti FW, Morgan DA, Gallo RC. Functional and morphologic characterization of human $\mathrm{T}$ cells continuously grown in vitro. $\mathrm{J}$ Immunol 1977;119:131-138.

2. Mizel SB, Farrar JJ. Revised nomenclature for antigen-nonspecific Tcell proliferation and helper factors. Cell Immunol 1979;48:433-436.

3. Feinerman O, Jentsch G, Tkach KE, et al. Single-cell quantification of IL-2 response by effector and regulatory $\mathrm{T}$ cells reveals critical plasticity in immune response. Mol Syst Biol 2010;6:437.

4. Waldmann TA, Kozak RW, Tsudo M, Oh-ishi T, Bongiovanni KF, Goldman CK. IL-2 receptors in adult T-cell leukemia: a target for immunotherapy. Hamatol Bluttransfus 1987;31:110-115.

5. Waldmann TA, O'Shea J. The use of antibodies against the IL-2 receptor in transplantation. Curr Opin Immunol 1998;10:507-512.

6. Waldmann TA. The IL-2/IL-15 receptor systems: targets for immunotherapy. J Clin Immunol 2002;22:51-56.

7. Queen C, Schneider WP, Selick HE, et al. A humanized antibody that binds to the interleukin 2 receptor. Proc Natl Acad Sci U S A 1989;86:10029-10033.

8. Wang X, Rickert M, Garcia KC. Structure of the quaternary complex of interleukin-2 with its alpha, beta, and gammac receptors. Science 2005;310:1159-1163.

9. Waldmann T, Tagaya Y, Bamford R. Interleukin-2, interleukin-15, and their receptors. Int Rev Immunol 1998;16:205-226.

10. Setoguchi R, Hori S, Takahashi T, Sakaguchi S. Homeostatic maintenance of natural Foxp3 $+\mathrm{CD} 25+\mathrm{CD} 4+$ regulatory $\mathrm{T}$ cells by interleukin (IL)-2 and induction of autoimmune disease by IL-2 neutralization. J Exp Med 2005;201:723-735.

11. Rickert M, Wang X, Boulanger MJ, Goriatcheva N, Garcia KC. The structure of interleukin-2 complexed with its alpha receptor. Science 2005;308:1477-1480.

12. Waldmann TA, Goldman CK, Bongiovanni KF, et al. Therapy of patients with human T-cell lymphotrophic virus I-induced adult Tcell leukemia with anti-Tac, a monoclonal antibody to the receptor for interleukin-2. Blood 1988;72:1805-1816.

13. Martin JF, Perry JS, Jakhete NR, Wang X, Bielekova B. An IL-2 paradox: blocking CD25 on T cells induces IL-2-driven activation of CD56(bright) NK cells. J Immunol 2010;185:1311-1320.

14. Goebel J, Stevens E, Forrest K, Roszman TL. Daclizumab (Zenapax) inhibits early interleukin-2 receptor signal transduction events. Transpl Immunol 2000;8:153-159.

15. Lehky TJ, Levin MC, Kubota R, et al. Reduction in HTLV-I proviral load and spontaneous lymphoproliferation in HTLV-Iassociated myelopathy/tropical spastic paraparesis patients treated with humanized anti-Tac. Ann Neurol 1998;44:942-947.

16. Nussenblatt RB, Fortin E, Schiffman R, et al. Treatment of noninfectious intermediate and posterior uveitis with the humanized anti-Tac mAb: a phase I/II clinical trial. Proc Natl Acad Sci U S A 1999;96:7462-7466.

17. Nussenblatt RB, Thompson DJ, Li Z, et al. Humanized antiinterleukin-2 (IL-2) receptor alpha therapy: long-term results in uveitis patients and preliminary safety and activity data for establishing parameters for subcutaneous administration. J Autoimmun 2003;21:283-293.

18. Bielekova B, Richert N, Howard T, et al. Humanized anti-CD25 (daclizumab) inhibits disease activity in multiple sclerosis patients failing to respond to interferon-beta. Proc Natl Acad Sci U S A 2004;101:8705-8708. 
19. Rose JW, Watt HE, White AT, Carlson NG. Treatment of multiple sclerosis with an anti-interleukin-2 receptor monoclonal antibody. Ann Neurol 2004;56:864-867.

20. Bielekova B, Howard T, Packer AN, et al. Effect of anti-CD25 antibody daclizumab in the inhibition of inflammation and stabilization of disease progression in multiple sclerosis. Arch Neurol 2009;66:483-489.

21. Rose JW, Burns JB, Bjorklund J, Klein J, Watt HE, Carlson NG. Daclizumab phase II trial in relapsing and remitting multiple sclerosis: MRI and clinical results. Neurology 2007;69:785-789.

22. Bielekova B, Richert N, Herman ML, et al. Intrathecal effects of daclizumab treatment of multiple sclerosis. Neurology 2011;77: 1877-1886.

23. Wynn D, Kaufman M, Montalban X, et al. Daclizumab in active relapsing multiple sclerosis (CHOICE study): a phase 2, randomised, double-blind, placebo-controlled, add-on trial with interferon beta. Lancet Neurol 2010;9:381-390.

24. Bielekova B, Becker B. Monoclonal antibodies in MS: mechanism of action. Neurology 2010;74(supplement 1):S31-S40.

25. Wakabayashi K, Lian ZX, Moritoki Y, et al. IL-2 receptor alpha(-/-) mice and the development of primary biliary cirrhosis. Hepatology 2006;44:1240-1249.

26. Willerford DM, Chen J, Ferry JA, Davidson L, Ma A, Alt FW. Interleukin-2 receptor alpha chain regulates the size and content of the peripheral lymphoid compartment. Immunity 1995;3:521-530.

27. Schorle H, Holtschke T, Hunig T, Schimpl A, Horak I. Development and function of $\mathrm{T}$ cells in mice rendered interleukin-2 deficient by gene targeting. Nature 1991;352:621-624.

28. Kundig TM, Schorle H, Bachmann MF, Hengartner H, Zinkernagel RM, Horak I. Immune responses in interleukin-2-deficient mice. Science 1993;262:1059-1061.

29. Suzuki H, Kundig TM, Furlonger C, et al. Deregulated T cell activation and autoimmunity in mice lacking interleukin-2 receptor beta. Science 1995;268:1472-1476.

30. Turka LA, Walsh PT. IL-2 signaling and CD4+ CD25+ Foxp3+ regulatory T cells. Front Biosci 2008;13:1440-1446.

31. Shevach EM, McHugh RS, Piccirillo CA, Thornton AM. Control of T-cell activation by CD4+ CD25+ suppressor T cells. Immunol Rev 2001;182:58-67.

32. Malek TR. The main function of IL-2 is to promote the development of T regulatory cells. J Leukoc Biol 2003;74:961-965.

33. Almeida AR, Legrand N, Papiernik M, Freitas AA. Homeostasis of peripheral CD4+ T cells: IL-2R alpha and IL-2 shape a population of regulatory cells that controls CD4+ T cell numbers. J Immunol 2002;169:4850-4860.

34. Van Parijs L, Refaeli Y, Lord JD, Nelson BH, Abbas AK, Baltimore D. Uncoupling IL-2 signals that regulate $\mathrm{T}$ cell proliferation, survival, and Fas-mediated activation-induced cell death. Immunity 1999;11:281-288

35. Lenardo MJ. Interleukin-2 programs mouse $\mathrm{T}$ lymphocytes for apoptosis. Nature 1991;353:858-861.

36. Hafler DA, Compston A, Sawcer S, et al. Risk alleles for multiple sclerosis identified by a genomewide study. N Engl J Med 2007;357:851-862.

37. Lowe CE, Cooper JD, Brusko T, et al. Large-scale genetic fine mapping and genotype-phenotype associations implicate polymorphism in the IL2RA region in type 1 diabetes. Nat Genet 2007;39:1074-1082.

38. Maier LM, Lowe CE, Cooper J, et al. IL2RA genetic heterogeneity in multiple sclerosis and type 1 diabetes susceptibility and soluble interleukin-2 receptor production. PLoS genetics 2009;5:e1000322.

39. Caudy AA, Reddy ST, Chatila T, Atkinson JP, Verbsky JW. CD25 deficiency causes an immune dysregulation, polyendocrinopathy, enteropathy, X-linked-like syndrome, and defective IL-10 expression from CD4 lymphocytes. J Allergy Clin Immunol 2007;119:482-487.
40. Roifman CM. Human IL-2 receptor alpha chain deficiency. Pediatr Res 2000;48:6-11.

41. Sharfe N, Dadi HK, Shahar M, Roifman CM. Human immune disorder arising from mutation of the alpha chain of the interleukin-2 receptor. Proc Natl Acad Sci U S A 1997;94:31683171.

42. Bielekova B, Catalfamo M, Reichert-Scrivner S, et al. Regulatory CD56bright natural killer cells mediate immunomodulatory effects of IL-2R-alpha-targeted therapy (daclizumab) in multiple sclerosis. PNAS 2006;103:5941-5946.

43. Oh U, Blevins G, Griffith C, et al. Regulatory T cells are reduced during anti-CD25 antibody treatment of multiple sclerosis. Arch Neurol 2009;66:471-479.

44. Baan CC, Balk AH, van Riemsdijk IC, et al. Anti-CD25 monoclonal antibody therapy affects the death signals of graftinfiltrating cells after clinical heart transplantation. Transplantation 2003;75:1704-1710.

45. Wuest SC, Edwan JH, Martin JF, et al. A role for interleukin-2 trans-presentation in dendritic cell-mediated $\mathrm{T}$ cell activation in humans, as revealed by daclizumab therapy. Nat Med 2011;17:604609 .

46. Biron CA, Brossay L. NK cells and NKT cells in innate defense against viral infections. Curr Opin Immunol 2001;13:458-464.

47. Orange JS. Unraveling human natural killer cell deficiency. J Clin Invest 2012;122:798-801.

48. Caligiuri MA. Human natural killer cells. Blood 2008;112:461-469.

49. Cooper MA, Fehniger TA, Caligiuri MA. The biology of human natural killer-cell subsets. Trends Immunol 2001;22:633-640.

50. Nishikawa K, Saito S, Morii T, et al. Accumulation of CD16CD56+ natural killer cells with high affinity interleukin 2 receptors in human early pregnancy decidua. Int Immunol 1991;3:743-750.

51. Guleria I, Sayegh MH. Maternal acceptance of the fetus: true human tolerance. J Immunol 2007;178:3345-3351.

52. Jacobs R, Hintzen G, Kemper A, et al. CD56bright cells differ in their KIR repertoire and cytotoxic features from CD56dim NK cells. Eur J Immunol 2001;31:3121-3127.

53. Fehniger TA, Cooper MA, Nuovo GJ, et al. CD56bright natural killer cells are present in human lymph nodes and are activated by T cell-derived IL-2: a potential new link between adaptive and innate immunity. Blood 2003;101:3052-3057.

54. Saito S, Nishikawa K, Morii T, et al. Cytokine production by CD16-CD56bright natural killer cells in the human early pregnancy decidua. Int Immunol 1993;5:559-563.

55. Moretta L, Biassoni R, Bottino C, et al. Human NK cells and their receptors. Microbes Infect 2002;4:1539-1544.

56. Kaiser BK, Pizarro JC, Kerns J, Strong RK. Structural basis for NKG2A/CD94 recognition of HLA-E. Proc Natl Acad Sci U S A 2008;105:6696-6701.

57. Jiang W, Chai NR, Maric D, Bielekova B. Unexpected Role for Granzyme K in CD56bright NK Cell-Mediated Immunoregulation of Multiple Sclerosis. J Immunol 2011;187:781-790.

58. Bovenschen N, Quadir R, van den Berg AL, et al. Granzyme K displays highly restricted substrate specificity that only partially overlaps with granzyme A. J Biol Chem 2009;284:3504-3512.

59. Bratke K, Kuepper M, Bade B, Virchow JC Jr., Luttmann W. Differential expression of human granzymes A, B, and $\mathrm{K}$ in natural killer cells and during CD8+ $\mathrm{T}$ cell differentiation in peripheral blood. Eur J Immunol 2005;35:2608-2616.

60. Gong JH, Maki G, Klingemann HG. Characterization of a human cell line (NK-92) with phenotypical and functional characteristics of activated natural killer cells. Leukemia 1994;8:652-658.

61. Dalbeth N, Gundle R, Davies RJ, Lee YC, McMichael AJ, Callan MF. CD56bright NK cells are enriched at inflammatory sites and can engage with monocytes in a reciprocal program of activation. $\mathrm{J}$ Immunol 2004;173:6418-6426. 
62. Rubenstein JL, Combs D, Rosenberg J, et al. Rituximab therapy for CNS lymphomas: targeting the leptomeningeal compartment. Blood 2003;101:466-468.

63. Perry JS, Han S, Xu Q, et al. Inhibition of LTi cell development by CD25 blockade Is associated with decreased intrathecal inflammation in multiple sclerosis. Sci Trans1 Med 2012;4:145ra06.

64. Caligiuri MA, Zmuidzinas A, Manley TJ, Levine H, Smith KA, Ritz J. Functional consequences of interleukin 2 receptor expression on resting human lymphocytes. Identification of a novel natural killer cell subset with high affinity receptors. J Exp Med 1990;171:1509-1526.

65. Elkins J, Sheridan J, Armaravadi L, Riester K, O'Neil G. CD56bright natural killer cell expansion predicts response to daclizumab HYP treatment in RRMS: Results of the SELECT trial. Neurology 2012;78:S31.004.

66. Vandenbark AA, Huan J, Agotsch M, et al. Interferon-beta-1a treatment increases CD56bright natural killer cells and CD4+CD25+ Foxp3 expression in subjects with multiple sclerosis. J Neuroimmunol 2009;215:125-128.

67. Reis EA, Athanazio DA, Lima I, et al. NK and NKT cell dynamics after rituximab therapy for systemic lupus erythematosus and rheumatoid arthritis. Rheumatol Int 2008;29(4):469-475.

68. De Jager PL, Rossin E, Pyne S, et al. Cytometric profiling in multiple sclerosis uncovers patient population structure and a reduction of CD8low cells. Brain 2008;131(pt 7):1701-1711.

69. Benczur M, Petranyl GG, Palffy G, et al. Dysfunction of natural killer cells in multiple sclerosis: a possible pathogenetic factor. Clin Exp Immunol 1980;39:657-662.

70. Kastrukoff LF, Morgan NG, Zecchini D, et al. A role for natural killer cells in the immunopathogenesis of multiple sclerosis. J Neuroimmunol 1998;86:123-133.

71. French AR, Yokoyama WM. Natural killer cells and autoimmunity. Arthritis Res Ther 2004;6:8-14.

72. Granucci F, Vizzardelli C, Pavelka N, et al. Inducible IL-2 production by dendritic cells revealed by global gene expression analysis. Nat Immunol 2001;2:882-888.

73. Driesen J, Popov A, Schultze JL. CD25 as an immune regulatory molecule expressed on myeloid dendritic cells. Immunobiology 2008;213:849-858.

74. Dubois S, Mariner J, Waldmann TA, Tagaya Y. IL-15-Ralpha recycles and presents IL-15 In trans to neighboring cells. Immunity 2002; 17:537-547.

75. Williams MA, Tyznik AJ, Bevan MJ. Interleukin-2 signals during priming are required for secondary expansion of CD8+ memory $\mathrm{T}$ cells. Nature 2006;441:890-893

76. Savo AM, Book BK, Henson S, Hakimi J, Pescovitz MD. Daclizumab rapidly saturates interleukin-2 receptor-alpha $(\mathrm{CD} 25)$ on lymph node lymphocytes in children. Transplant Proc 1999;31:11821183.

77. Sawa S, Cherrier M, Lochner M, et al. Lineage relationship analysis of RORgammat+ innate lymphoid cells. Science 2010;330:665-669.

78. Spits H, Di Santo JP. The expanding family of innate lymphoid cells: regulators and effectors of immunity and tissue remodeling. Nat Immunol 2011;12:21-27.

79. Yokota Y, Mansouri A, Mori S, et al. Development of peripheral lymphoid organs and natural killer cells depends on the helix-loophelix inhibitor Id2. Nature 1999;397:702-706.
80. Aloisi F, Pujol-Borrell R. Lymphoid neogenesis in chronic inflammatory diseases. Nat Rev Immunol 2006;6:205-217.

81. Lochner M, Ohnmacht C, Presley L, et al. Microbiota-induced tertiary lymphoid tissues aggravate inflammatory disease in the absence of RORgamma t and LTi cells. J Exp Med 2011;208:125-134.

82. Withers DR, Gaspal FM, Mackley EC, et al. Cutting edge: lymphoid tissue inducer cells maintain memory cd4 $\mathrm{t}$ cells within secondary lymphoid tissue. J Immunol 2012;189(5):2094-2098.

83. Lane PJ, Gaspal FM, McConnell FM, Kim MY, Anderson G, Withers DR. Lymphoid tissue inducer cells: innate cells critical for CD4 (+) T cell memory responses? Ann N Y Acad Sci 2012;1247:1-15.

84. Howell OW, Reeves CA, Nicholas R, et al. Meningeal inflammation is widespread and linked to cortical pathology in multiple sclerosis. Brain 2011;134(9):2755-2771.

85. Magliozzi R, Howell O, Vora A, et al. Meningeal B-cell follicles in secondary progressive multiple sclerosis associate with early onset of disease and severe cortical pathology. Brain 2007;130(pt 4):1089-1104.

86. Magliozzi R, Columba-Cabezas S, Serafini B, Aloisi F. Intracerebral expression of CXCL13 and BAFF is accompanied by formation of lymphoid follicle-like structures in the meninges of mice with relapsing experimental autoimmune encephalomyelitis. J Neuroimmunol 2004;148:11-23.

87. Scheibenbogen C, Keilholz U, Richter M, Andreesen R, Hunstein $\mathrm{W}$. The interleukin-2 receptor in human monocytes and macrophages: regulation of expression and release of the alpha and beta chains (p55 and p75). Res Immunol 1992;143:33-37.

88. Kniep EM, Strelow I, Lohmann-Matthes ML. The monocyte interleukin-2 receptor light chain: production of cell-associated and soluble interleukin-2 receptor by monocytes. Immunology 1992;75:299-304.

89. Maier LM, Anderson DE, Severson CA, et al. Soluble IL-2RA levels in multiple sclerosis subjects and the effect of soluble IL2RA on immune responses. J Immunol 2009;182:1541-1547.

90. Mesarovic MD, Sreenath SN, Keene JD. Search for organising principles: understanding in systems biology. Syst Biol (Stevenage) 2004;1:19-27.

91. Schneider R, Arbour N. Journal club: intrathecal effects of daclizumab treatment of multiple sclerosis. Neurology 2012;78:e131-e133.

92. Liu J, Wang L, Zhan SY, Xia Y. Daclizumab for relapsing remitting multiple sclerosis. Cochrane Database Syst Rev 2012;4:CD008127.

93. Gold R, Giovannoni G, Selmaj K, et al. A randomized, doubleblind, placebo-controlled study to evaluate the safety and efficacy of daclizumab HYP monotherapy in relapsing-remitting multiple sclerosis: primary results of the SELECT trial. Neurology 2012;78: S01.005.

94. Moroso V, Metselaar HJ, Mancham S, et al. Liver grafts contain a unique subset of natural killer cells that are transferred into the recipient after liver transplantation. Liver Transpl 2010;16:895-908.

95. Hengster P, Pescovitz MD, Hyatt D, Margreiter R. Cytomegalovirus infections after treatment with daclizumab, an anti IL-2 receptor antibody, for prevention of renal allograft rejection. Roche Study Group. Transplantation 1999;68:310-313.

96. Webster AC, Playford EG, Higgins G, Chapman JR, Craig JC. Interleukin 2 receptor antagonists for renal transplant recipients: a meta-analysis of randomized trials. Transplantation 2004;77:166-176. 